\title{
DESEMPENHO ENERGÉTICO DE FACHADAS ENVIDRAÇADAS EM CLIMAS BRASILEIROS
}

ANDREIS, Cínthia (1); BESEN, Priscila (2); WESTPHAL, Fernando Simon (3)

(1) Universidade Federal de Santa Catarina, e-mail: cinthiaandreis@gmail.com, (2) Universidade Federal de Santa Catarina, e-mail: pribesen@gmail.com, (3) Universidade Federal de Santa Catarina, e-mail: fernandosw@arq.ufsc.br

\begin{abstract}
RESUMO
Edificações com grandes áreas envidraçadas nas fachadas vêm se consolidando como um estilo internacional de arquitetura de escritórios, mesmo que sua eficiência energética seja amplamente questionada em condições bioclimáticas brasileiras. Baseado nesse questionamento, o presente estudo tem como objetivo a determinação e análise dos impactos gerados por diferentes configurações de fachadas no consumo energético de edifícios de escritórios em condições bioclimáticas brasileiras. Utilizou-se o software de simulação EnergyPlus para modelar diferentes condições de fachada para um edifício de escritórios. Os parâmetros analisados são: percentual de abertura na fachada (WWR), tipos de vidro, configurações de fachada (exposta ou completamente revestida) e uso de isolante térmico. São analisadas sete cidades brasileiras: Curitiba, Recife, São Paulo, Brasília, Porto Alegre, Salvador e Rio de Janeiro. Os resultados obtidos mostram que o desempenho energético de edifícios com grandes áreas envidraçadas é afetado especialmente pelo WWR e pelo tipo de vidro das aberturas, podendo-se obter desempenhos semelhantes em modelos com WWR diferentes alterando-se exclusivamente a especificação do fechamento envidraçado. Fachadas completamente revestidas acarretam aumento determinante do consumo energético em todas as condições bioclimáticas analisadas. Quanto ao tipo de vidro, verificou-se que em climas quentes, como Recife, Salvador e Rio de Janeiro, o uso de vidros duplos de controle solar foi mais eficiente. Em Curitiba, São Paulo e Brasília, o vidro laminado de controle solar obteve desempenho semelhante ou melhor do que vidros duplos.
\end{abstract}

Palavras-chave: Fachadas envidraçadas, consumo de energia, edifício de escritórios.

\begin{abstract}
Buildings with high glazed areas in the façade are being reinforced as an international style of commercial architecture, even though its energy efficiency being widely questioned in Brazilian bioclimatic condition. Based on this question, the aim of this work is to define and to analyze the impacts of different configurations of glazed façades in the energy consumption of office buildings in Brazil. The EnergyPlus software was used to simulate different options of façades to an artificially conditioned office building with 20 floors. The analysis focused in the parameters: window to wall ratio (WWR), type of glass, façade skin configuration (completely covered by glass or not) and the usage of thermal insulation. Seven Brazilian cities were considered in the study: Curitiba, Recife, São Paulo, Brasília, Porto Alegre, Salvador and Rio de Janeiro. The results show that the energy performance of buildings with high glazed areas were affected specially by the WWR and by the type of the glass, performing similar behavior in models with different WWR, when changing the specification of the glass. Fully glazed façades result in significant increase of energy consumption in all the bioclimatic conditions under analysis. Regarding the type of glass, it was observed that in hot weather, such as Recife, Salvador and Rio de Janeiro, the use of insulated glass units were more efficient. However, in Curitiba, São Paulo and Brasilia, the laminated glass(without air gap) obtained similar performance or even better than insulated glazing.
\end{abstract}

Keywords: Glazed façade, energy consumption, office buildings. 


\section{INTRODUÇÃO}

Edificações com grandes áreas envidraçadas vêm se consolidando como um estilo internacional de arquitetura não residencial adotado nos mais diversos países e condições bioclimáticas, inclusive no Brasil. As principais justificativas para optar-se por fachadas envidraçadas, segundo Shameri et al. (2011), são: transparência e possibilidade de integração visual com o exterior, admissão de luz natural no interior, além de ser um atrativo estético valorizado por investidores e projetistas. Por outro lado, o desempenho térmico e energético destas edificações nas condições bioclimáticas brasileiras tem sido amplamente questionado.

A envoltória da edificação deve atuar como um filtro entre as condições internas e externas, servindo de controle para a entrada de ar, calor, frio, luz, ruídos e odores. Com relação ao consumo do sistema de condicionamento de ar, Palmer \& Gentry (2012) afirmam que os vidros compõem uma das maiores complexidades entre os componentes da edificação, influenciando o conforto térmico e visual e, especialmente, o consumo energético. $\mathrm{O}$ avanço tecnológico (computadores e equipamentos) elevou a carga interna de edifícios de escritórios, enquanto que fachadas envidraçadas, geralmente sem sombreamento, se tornaram muito comuns, sendo necessárias algumas precauções para evitar o superaquecimento do edifício. (GRATIA; DE HERDE, 2007)

Besen e Westphal (2012) desenvolveram uma análise de conforto térmico e desempenho energético de fachadas com vidros laminados e vidros duplos em quatro cidades brasileiras: São Paulo, Rio de Janeiro, Fortaleza e Curitiba, ratificando que, quanto maior o WWR (window-to-wall ratio) e o fator solar, maior o consumo energético. Comparando-se vidros laminados e duplos, constatou-se que ambos geram desempenho energético semelhante em Curitiba e São Paulo, enquanto que em Fortaleza e Rio de Janeiro vidros duplos de controle solar promovem maior economia, visto que aumentam o isolamento térmico da edificação, reduzindo as trocas térmicas entre o interior e o exterior da edificação. Avaliando-se Fator Solar (FS) dos vidros e WWR, Yamakawa e Westphal (2009) constataram por meio de simulação computacional que, empregando-se vidros de alto desempenho FS $25 \%$ em fachadas com WWR 60\%, o consumo energético do modelo equivale ao uso de vidro com FS $45 \%$ e WWR $30 \%$. Evidencia-se, portanto, a importância da especificação adequada não só da área de abertura na fachada, mas também do tipo de vidro. Análises paramétricas de elementos da envoltória foram realizadas por diversos pesquisadores, com o objetivo de determinar e avaliar o impacto da sua variação no comportamento térmico e energético da edificação em diferentes climas, como é o caso de Yamakawa e Westphal (2009), Santana e Ghisi (2009), Cavalcante (2010), Westphal (2007), Carvalho et al. (2010) no Brasil, assim como Buratti et al. (2012), (Yin et al. (2012), Poirazis et al. (2008), NohPat et al. (2011), Motta (2007), Bouden (2007), Gratia e De Herde (2007) e Palmer e Gentry (2012) no cenário internacional.

A respeito de fachadas completamente revestidas por vidro, Neveen (2008) enfatiza que as pesquisas são desenvolvidas prioritariamente para climas frios e moderados, mesmo que esta configuração de fachada seja atualmente exportada para os mais diferentes climas. Gratia e de Herde (2007) alertam sobre a elevação da carga térmica interna quando adicionada uma segunda camada à fachada (revestimento envidraçado externo), injetando-se ar quente para os escritórios, proveniente do aquecimento da câmara de ar entre as camadas da fachada.

Neveen (2008) estima que as fachadas sejam responsáveis por aproximadamente $45 \%$ da carga de resfriamento da edificação, evidenciando a importância da sua composição e especificação adequada dos materiais para melhoria do desempenho energético do 
sistema de condicionamento de ar. Com base nisso, a presente pesquisa de caráter experimental tem como objetivo exploratório determinar, por meio de simulação computacional, o desempenho energético de edifícios de escritórios condicionados artificialmente, verificando os impactos gerados por diferentes parâmetros relativos a fachadas envidraçadas em diversas condições bioclimáticas brasileiras. Os parâmetros avaliados são: área envidraçada na fachada, tipo de vidro, tipo de configuração de fachada, uso de isolante na viga de borda da fachada e localização do edifício. Os resultados parciais da pesquisa de mestrado são obtidos a partir das simulações computacionais que geram dados de consumo do sistema de condicionamento de ar para cada condição do modelo, apontando-se os impactos gerados por cada parâmetro no desempenho energético anual e as melhores configurações para cada cidade analisada dentre os parâmetros avaliados. Este estudo não considera integração do sistema de iluminação artificial com a iluminação natural, nem elementos de sombreamento externo e entorno, utilizando exclusivamente sistema de persianas internas automatizadas em todos os casos.

\section{METODOLOGIA}

O método de verificação e análise do consumo energético de edificações com fachadas envidraçadas nas diversas condições bioclimáticas brasileiras baseia-se na utilização de ferramenta de simulação computacional, o software EnergyPlus. Com base nos resultados das simulações quanto ao consumo energético anual do sistema de condicionamento artificial de ar, determinam-se os parâmetros que acarretam maior variação de consumo. Além disso, verificam-se quais os materiais e configurações de fachadas que promovem melhor desempenho energético em cada cidade analisada nessa amostra.

\subsection{Modelo base de simulação}

O edifício base da presente pesquisa utiliza como referência o modelo computacional de simulação adotado por Besen e Westphal (2012), cujas características estão apresentadas na Tabela 1, representando um edifício de escritórios retangular condicionado artificialmente, com planta livre e 20 pavimentos tipo, divididos em cinco zonas térmicas cada, sendo escritórios nas zonas periféricas (condicionadas) e zona de serviços no centro (não condicionada), conforme a Figura 1. As quatro fachadas consideram condições idênticas de WWR, tipo de vidro, tipo de parede e revestimento. $\mathrm{O}$ edifício base mantem determinadas características fixas, sendo as principais: cobertura e lajes em concreto, paredes externas em alvenaria $\left(U=1,96 \mathrm{~W} / \mathrm{m}^{2} \mathrm{~K}\right)$ e paredes internas em gesso acartonado.

\section{Figura 1 - Vista em perspectiva e zoneamento térmico do modelo de simulação}
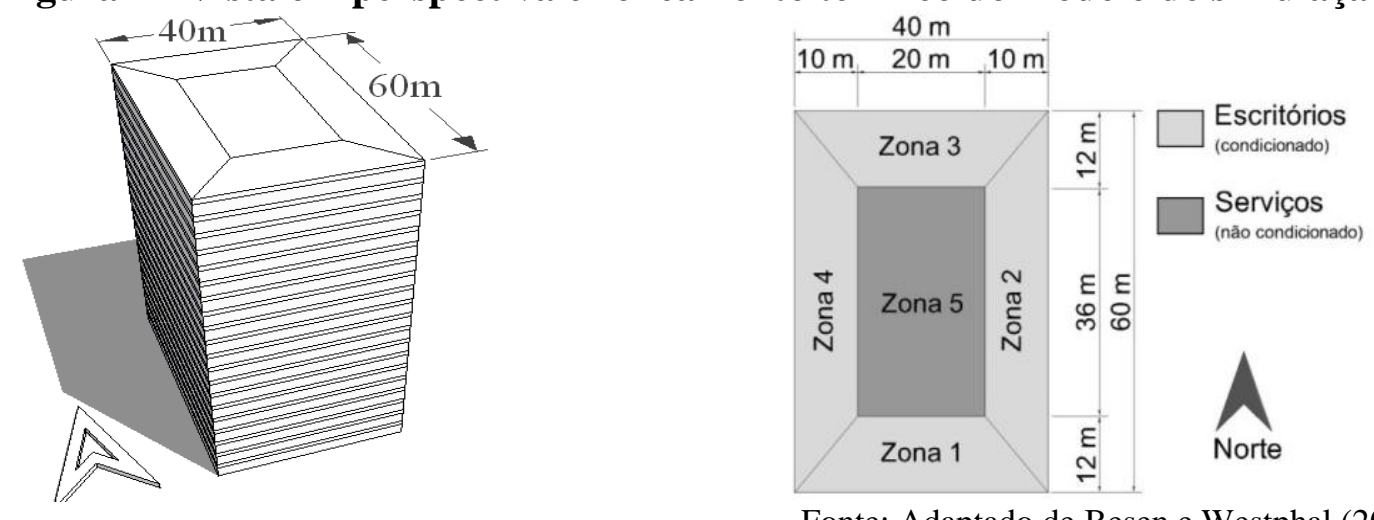

Fonte: Adaptado de Besen e Westphal (2012) 
Tabela 1 - Características principais do edifício considerado nas análises.

\begin{tabular}{|l|l|}
\hline Característica & Descrição \\
\hline Dimensões & $\begin{array}{l}\text { Comprimento x Largura: } 60,0 \mathrm{~m} \text { x } 40,0 \mathrm{~m} \\
\text { Zona de serviços: } 36 \mathrm{~m} \times 20 \mathrm{~m} \\
\text { Altura de laje a laje: } 4,0 \mathrm{~m} \text {; Pé-direito de } 2,8 \mathrm{~m} \\
\text { Total de } 20 \text { Pavimentos }\end{array}$ \\
\hline Área total construída & $48.000 \mathrm{~m}^{2}$ \\
\hline Área condicionada & $33.600 \mathrm{~m}^{2}(70 \%$ do total) \\
\hline Sistema de condicionamento de ar & Água gelada com centrífugas de COP=6,10 W/W \\
\hline Termostato & Aquecimento a $20^{\circ} \mathrm{C}$ e resfriamento a $24^{\circ} \mathrm{C}$ \\
\hline Sombreamento & $\begin{array}{l}\text { Persianas internas de acionamento automático, quando a } \\
\text { radiação solar é maior que } 200 \mathrm{~W} / \mathrm{m}^{2}\end{array}$ \\
\hline Ocupação & Densidade de ocupação no edifício: $8 \mathrm{~m} / 2$ pessoa \\
\hline Sistema de iluminação & Densidade de potência nos escritórios: $12 \mathrm{~W} / \mathrm{m}^{2}$ \\
\hline Demais equipamentos internos & Densidade de potência nos escritórios: $16 \mathrm{~W} / \mathrm{m}^{2}$ \\
\hline Cargas condominiais & Total: $213 \mathrm{~kW}$ (cerca de $15 \%$ do consumo total) \\
\hline
\end{tabular}

Os padrões de uso de pessoas (Figura 2) e do sistema de condicionamento de ar (Figura 3) utilizados nos modelos de simulação ocorrem de maneiras distintas em dias úteis (segunda a sexta-feira) e sábados, sendo que não há utilização em domingos e feriados.

Figura 2- Padrões de uso: Pessoas

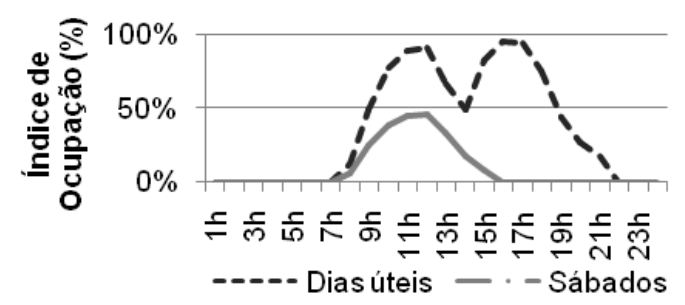

Figura 3 - Padrões de uso: Sistema de Condicionamento de Ar

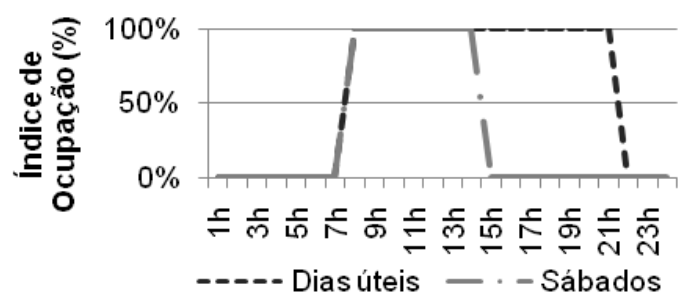

\subsection{Parâmetros variáveis de simulação}

O ganho de calor através das aberturas é influenciado por algumas variáveis principais, sendo elas: orientação, tamanho da abertura, tipo de vidro e proteções solares (internas ou externas), influenciando diretamente a demanda energética do sistema de condicionamento de ar. Baseando-se nos principais fatores relativos às fachadas que impactam o desempenho energético de edificações, determinaram-se os parâmetros variáveis de estudo:

a) Percentual de área envidraçada nas fachadas (WWR): 30\%; 40\%; 50\%; 60\%;

b) Tipo de vidro: Incolor $(6 \mathrm{~mm})$; Verde $(6 \mathrm{~mm})$; Laminado de controle solar (12mm); Duplo de controle solar $(6+12+6 \mathrm{~mm})$;

c) Localização: Curitiba (PR) - ZB 1; São Paulo (SP) - ZB 3; Porto Alegre (RS) ZB 3; Brasília (DF) - ZB 5; Rio de Janeiro (RJ) - ZB 8; Salvador (BA) - ZB 8; Recife (PE) - ZB 8;

d) Configuração das fachadas: exposta e completamente revestida por vidro;

e) Isolante térmico em viga de borda de fachadas revestidas: com e sem isolante.

As configurações dos fechamentos envidraçados das fachadas são apresentados na Figura 4, enquanto que suas propriedades térmicas e ópticas são dispostas na Tabela 2. 
Figura 4 - Configuração dos vidros analisados
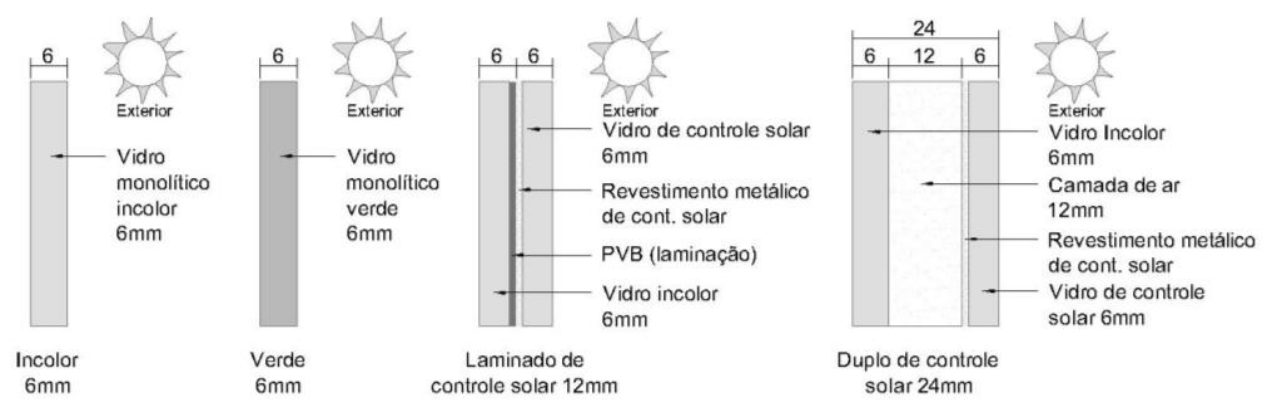

Tabela 2: Propriedades térmicas e ópticas dos vidros adotados no estudo.

\begin{tabular}{|l|c|c|c|c|c|c|c|}
\hline \multirow{2}{*}{ Propriedade } & \multirow{2}{*}{ Incolor } & \multirow{2}{*}{ Verde } & \multirow{2}{*}{$\begin{array}{c}\text { Controle } \\
\text { Solar }\end{array}$} & \multirow{2}{*}{$\begin{array}{c}\text { Revest. } \\
\text { Externo }\end{array}$} & \multicolumn{3}{|c|}{ Duplo (câm. ar 12mm) } \\
\cline { 5 - 9 } & & & & Vid. Ext. & Vid. Int. & Total \\
\hline Espessura (mm) & 6 & 6 & 12 & 10 & 6 & 6 & 24 \\
\hline Transmissão visível (\%) & 88 & 75 & 30 & 12 & 44 & 88 & 39 \\
\hline $\begin{array}{l}\text { Transmitância Térmica } \\
\left(\mathrm{W} / \mathrm{m}^{2} . \mathrm{K}\right)\end{array}$ & 5,80 & 5,79 & 5,60 & 5,60 & \multicolumn{4}{|c|}{2,09} \\
\hline Fator Solar (\%) & 84 & 62 & 33 & 33 & 35 & 84 & 28 \\
\hline
\end{tabular}

\subsubsection{Configurações de fachadas}

Os modelos de simulação compreendem duas configurações de fachadas, que são: fachada exposta e fachada revestida por vidro. No caso da fachada exposta (Figura 5), o vidro só é utilizado no fechamento dos vãos das aberturas, que variam de acordo com o percentual de área envidraçada (WWR) do modelo. No caso da fachada revestida (Figura 6), além do fechamento envidraçado dos vãos (cujas propriedades variam de acordo com o parâmetro "Tipo de Vidro"), as fachadas são completamente revestidas por vidro branco, cujas características e propriedades encontram-se na Tabela 2.

Figura 5 - Corte esquemático de fachada exposta

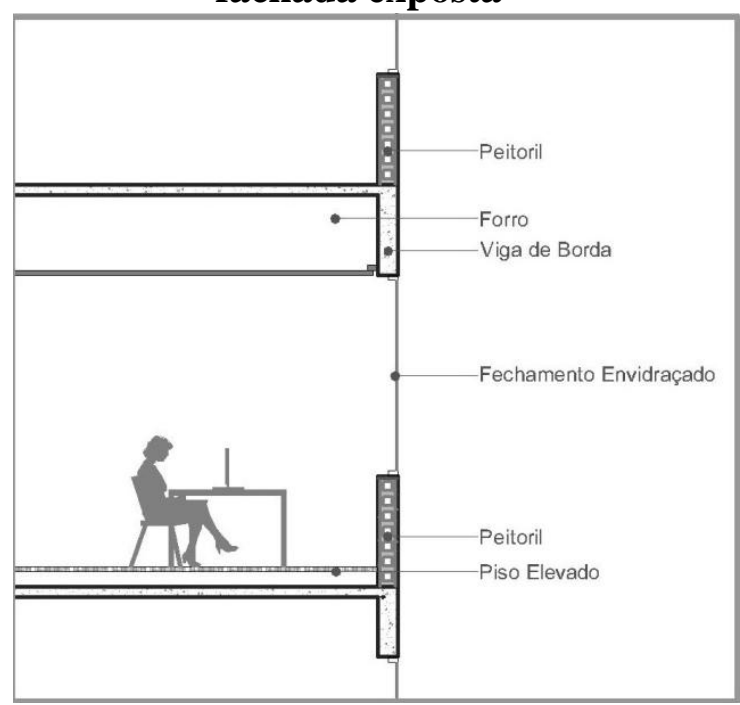

Figura 6 - Corte esquemático de fachada completamente revestida por vidro

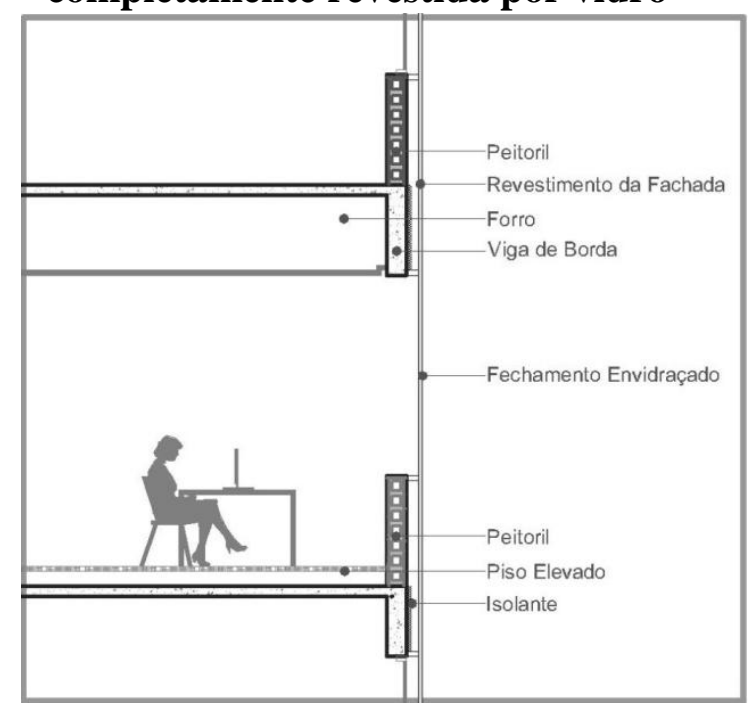

No caso da fachada revestida, considerou-se peitoril e viga de borda expostos diretamente à camada de ar entre a parede e o revestimento envidraçado externo, além de uma variação considerando a aplicação de $50 \mathrm{~mm}$ de isolante térmico na face externa da viga de borda, em contato com a camada de ar. 


\section{RESULTADOS}

Os resultados de consumo energético para condicionamento de ar compreendem a demanda de aquecimento e resfriamento, sendo que o consumo para aquecimento representou no máximo $1,76 \%$ do total em Porto Alegre e 1,25\% em Curitiba, cidades com períodos de frio intenso. Nas demais cidades não houve necessidade de aquecimento, visto que a carga térmica da edificação garante a temperatura mínima interna ao longo de todo o ano. Investigando-se a variação do tipo de fechamento envidraçado e WWR (área de janela), como era esperado com base nos resultados obtidos por Besen e Westphal (2012), ratificou-se que quanto maior o WWR, maior o consumo energético para condicionamento de ar, mantendo o mesmo tipo de vidro. Por outro lado, o desempenho energético depende diretamente do tipo de vidro utilizado nas fachadas. Percebe-se que WWR $60 \%$ combinado ao fechamento adequado pode promover melhor desempenho do que WWR 30\% com vidro de pior desempenho, que é o caso da cidade de Curitiba, na qual a aplicação de vidro laminado de controle solar com WWR 60\% promove desempenho semelhante ao vidro verde com WWR 30\%. Em Brasília, o desempenho de vidro verde e WWR $40 \%$ é semelhante ao laminado de controle solar e WWR $60 \%$, ocorrência que se repete em outras cidades de estudo, conforme se percebe na Figura 7, que apresenta o consumo anual do sistema de condicionamento de ar decorrente da variação de WWR e tipo de vidro em diferentes cidades brasileiras.

Figura 7 - Variação do WWR e Tipo de Vidro x Variação do Consumo

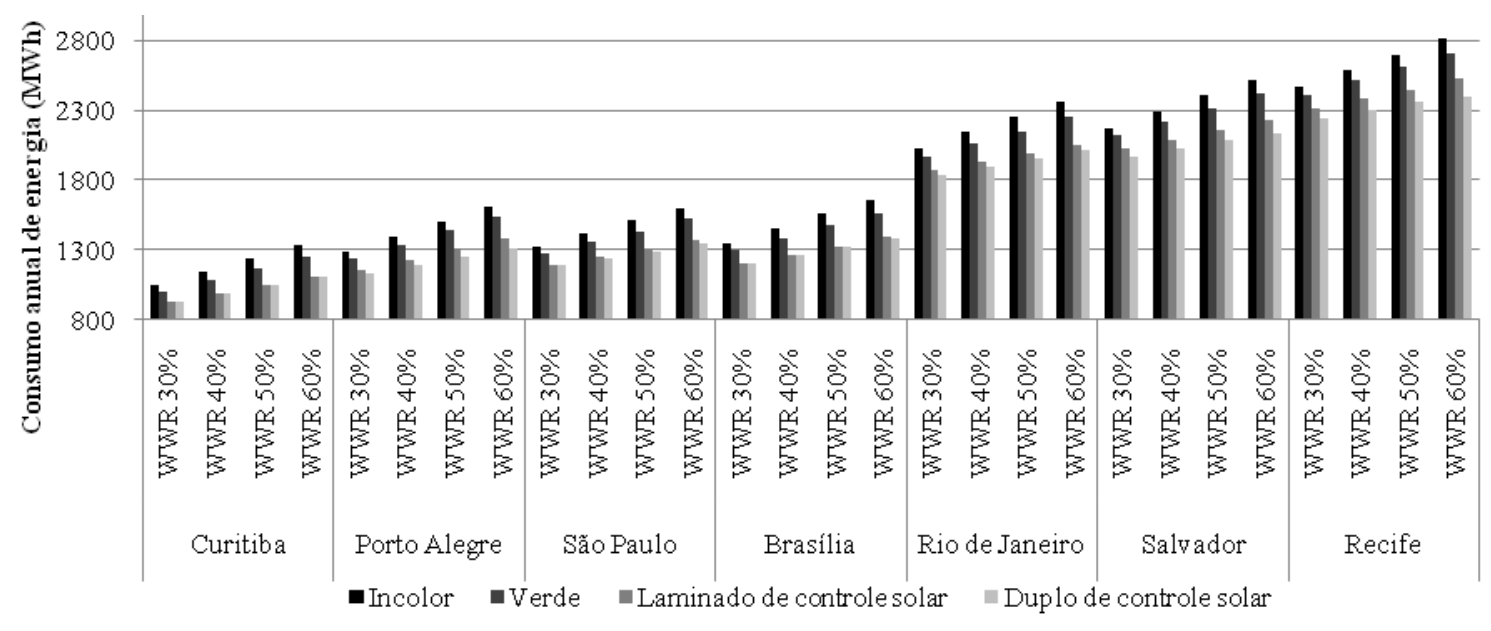

O desempenho dos vidros analisados (incolor, verde, laminado de controle solar e duplo de controle solar) evidencia a importância da especificação adequada do tipo de vidro. Em climas medianos, como São Paulo e Brasília, o desempenho energético decorrente do uso de vidro laminado e vidro duplo, ambos de controle solar, foi similar. Nesses casos as grandes diferenças entre a temperatura do ar interno e externo são pouco frequentes ao longo do ano. Nas cidades frequentemente quentes o uso do vidro duplo traz maiores benefícios. Em clima frio como o da cidade de Curitiba, onde poderia haver grande consumo de energia para aquecimento, o vidro duplo não trouxe economia significativa pelo fato do edifício em questão ser de escritórios, com alta densidade de carga interna.

Analisando-se separadamente o impacto do aumento do WWR (sem que haja alteração do tipo de vidro) no desempenho da edificação, percebe-se que o aumento do consumo energético não é proporcional ao aumento do WWR. Ampliando-se WWR de 30\% para $60 \%$ com uso de vidro duplo, o aumento do consumo anual para condicionamento de ar 
é semelhante para diferentes cidades, sendo que em Recife foi de $157 \mathrm{MWh}(+7,0 \%)$, no Rio de Janeiro 171,7 MWh (+9,3\%), e em Curitiba 181,6 MWh (+19,6\%), evidenciando que em climas muito quentes o aumento percentual do consumo quando se amplia o WWR é menor, visto que o consumo total do sistema de condicionamento de ar é naturalmente mais elevado devido à grande participação do ganho de calor por condução através das paredes e da carga térmica proveniente do ar exterior de renovação. Alterando-se o WWR e o tipo de vidro verificou-se que, em São Paulo, por exemplo, vidro de controle solar e WWR 60\% consomem 95,6 MWh $(+7,5 \%)$ a mais do que o modelo com vidro verde e WWR 30\%. Desta maneira, é de suma importância analisar cada situação específica e determinar a melhor configuração de fachada, levando em consideração o aumento efetivo do consumo de energia quando se amplia o WWR. A Figura 8apresenta o aumento do WWR e do consumo em condicionamento de ar para Curitiba, Brasília e Salvador, utilizando-se vidro laminado de controle solar em edificações com fachada exposta.

Figura 8 - Variação do consumo em função da variação do WWR

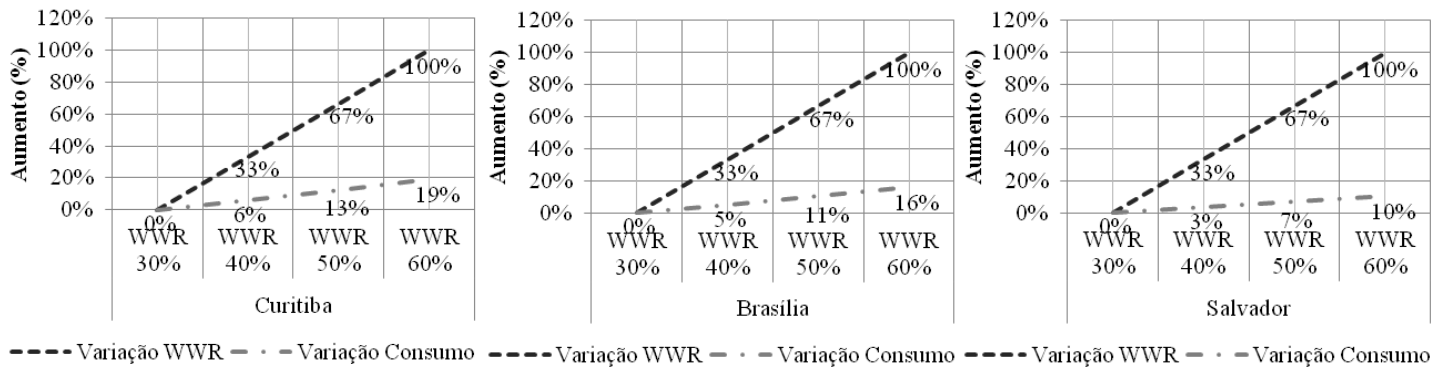

De acordo com a Figura 8 verifica-se que o aumento do WWR acarreta o aumento do consumo em todas as cidades analisadas. Contudo, o aumento do consumo é muito menor do que o aumento da área de transparência da fachada. Em Curitiba, por exemplo, duplicando-se a área de janela, o consumo aumenta 19\%, em Brasília 16\%, enquanto que em Salvador o consumo aumenta 10\%. Desta maneira, WWR maiores podem ser utilizados de acordo com a necessidade do projeto, buscando-se ampliar o contato visual com o meio externo, e maior aproveitamento da iluminação natural. Os ensaios realizados neste trabalho indicam como a especificação adequada do fechamento transparente pode compensar o aumento da área de janela na fachada.

Com relação ao comportamento de fachadas expostas e revestidas, em todas as condições bioclimáticas analisadas a configuração de fachada exposta promove melhor desempenho energético, conforme se observa nos gráficos da Figura 9. Verifica-se que quanto menor o WWR, maior a economia energética decorrente do uso de fachadas expostas em comparação a fachadas revestidas, já que a área de parede revestida é menor. O tipo de vidro que promove maior variação do consumo é o vidro duplo, já que quando utilizado em fachadas expostas, diminui o ganho de calor externo devido ao maior isolamento das aberturas e, no caso de fachadas revestidas, o maior isolamento dificulta a dissipação do calor absorvido pela envoltória para o meio externo.

Em fachadas expostas, que possuem uma parte opaca e outra transparente, a fachada permite com mais facilidade a dissipação do calor interno para o ambiente externo, reduzindo o consumo para resfriamento da edificação. Por outro lado, edifícios com fachadas completamente revestidas de vidro possuem maior isolamento térmico, além do efeito estufa criado entre o elemento transparente e opaco (geralmente peitoril e viga de borda), elevando a carga térmica interna e consequentemente o consumo para resfriamento do ar. 
As maiores variações no consumo foram observadas em climas quentes, como Rio de Janeiro, Recife e Salvador, enquanto que a diferença foi menor em Curitiba, São Paulo e Brasília. A maior variação no consumo, considerando-se vidro laminado de controle solar, ocorreu no Rio de Janeiro, no modelo com WWR de 30\%, quando a fachada revestida consumiu $249,3 \mathrm{MWh}(+13,3 \%)$ a mais do que fachada não revestida. A menor variação ocorreu para a cidade de Curitiba e WWR 60\%, aumentando em 108,9 MWh $(+9,8 \%)$ o consumo de energia elétrica para condicionamento de ar.

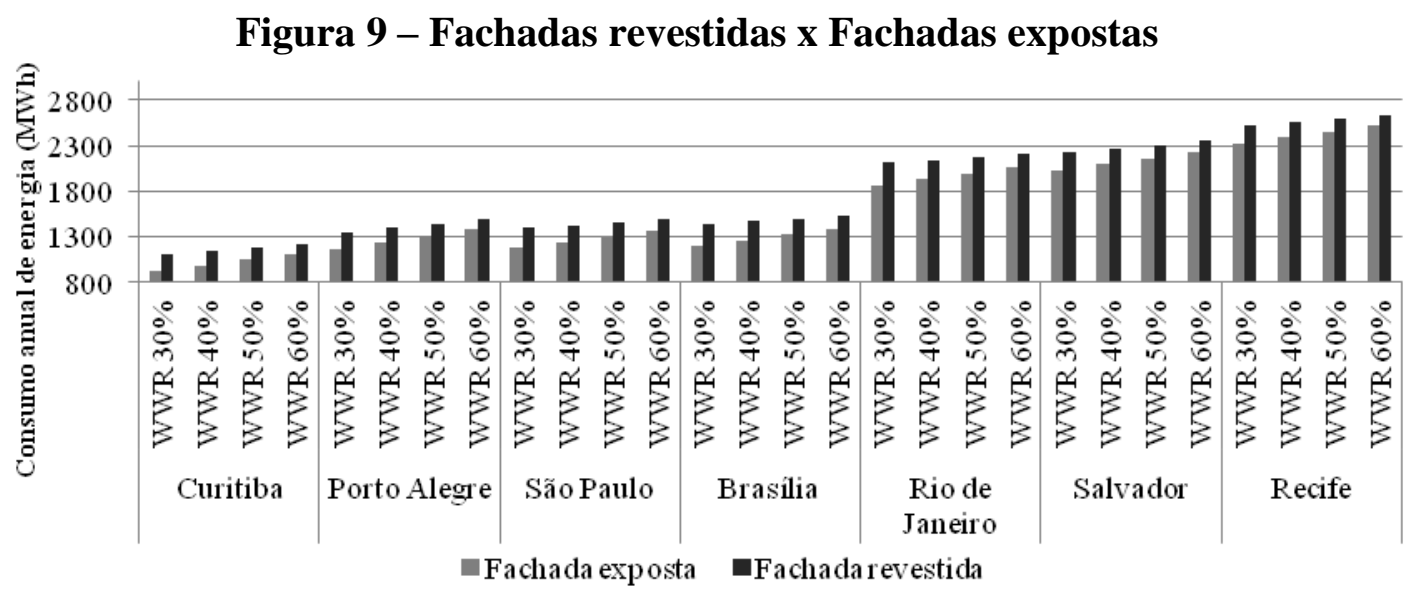

Para atenuar o efeito estufa nas fachadas completamente revestidas de vidro, foi simulada a utilização de isolamento térmico na viga de borda em contato com a câmara de ar. Neste caso, houve ligeira redução no consumo de energia para condicionamento de ar, conforme observa-se nos gráficos da Figura 10, relativo aos WWR 30\% e 60\% para cada tipo de vidro e cidade. Recife, Salvador e Rio de Janeiro denotaram a maior variação no consumo quando utilizado isolante térmico, entre 53,44 MWh $(2,27 \%)$ no Rio de Janeiro e 85,05 MWh (3,58\%) em Recife, evidenciando a importância deste elemento na composição da envoltória do edifício, principalmente em climas quentes. Em Curitiba a economia máxima relativa à aplicação de isolante foi de 24,36 MWh (2,04\%), em Porto Alegre de 47,88 MWh (3,44\%), em São Paulo de 36,25 MWh $(2,51 \%)$ e em Brasília de 54,78 MWh (3,28\%). Pode-se perceber com base nestes dados que a variação percentual do consumo em edifícios localizados em cidades com clima muito quente é menor, devido ao consumo total de condicionamento de ar ser elevado.

\section{Figura 10 - Redução do consumo com uso de isolante em fachadas revestidas para} WWR 30\% e WWR 60\%
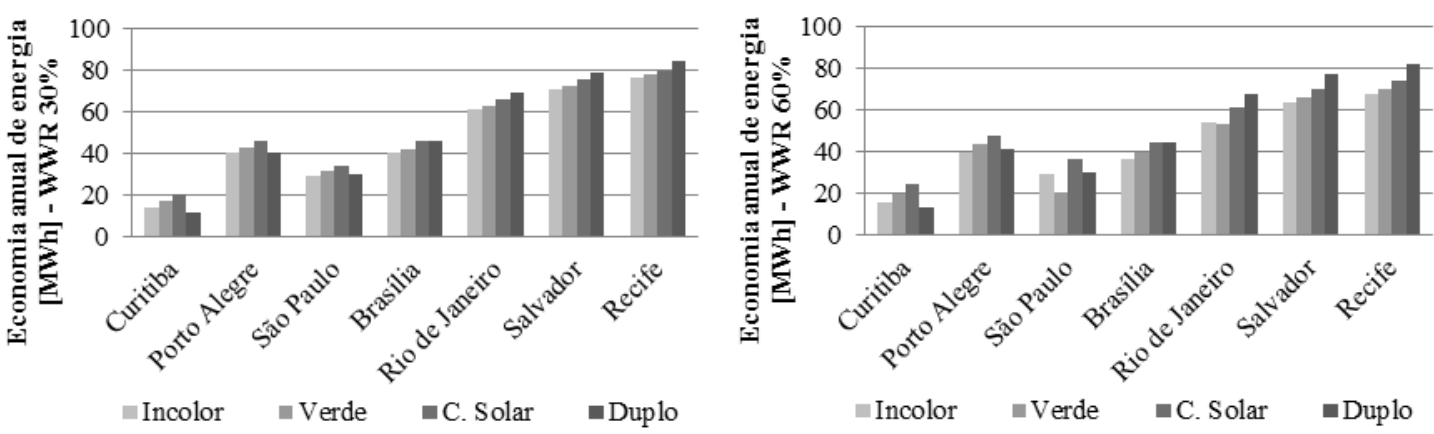

\section{CONCLUSÕES}

Este trabalho apresentou uma análise energética de diferentes composições de fachadas para um edifício de escritórios por meio de simulação computacional. As simulações consideraram a variação de tipo de vidro, percentual de área envidraçada na fachada 
(WWR), configuração das fachadas (expostas ou completamente revestidas) e uso de isolante térmico nas paredes externas.

Os resultados apontam para a importância da simulação detalhada de edificações com grandes áreas envidraçadas, levando-se em consideração o clima em que se inserem. Verificou-se um melhor desempenho de fachadas expostas quando comparadas a fachadas completamente revestidas por vidro, sendo que as maiores variações de consumo ocorrem efetivamente quando comparados modelos com fachadas expostas e fachadas revestidas por vidro. Também se percebe que, apesar de a área de janela ter influência no desempenho energético dos modelos, uma especificação mais adequada do tipo de vidro promove melhoria considerável da eficiência energética da edificação. O aumento do WWR não acarreta aumento do consumo na mesma proporção, pois as janelas representam apenas uma parcela da carga térmica total da edificação. Observouse que dobrando a área transparente da fachada, o aumento no consumo de energia para condicionamento de ar foi de $10 \%$ a $20 \%$, dependendo do clima.

Quanto ao tipo de fechamento envidraçado constatou-se que, apesar de vidros duplos serem considerados uma boa opção para aplicação em climas extremos (muito frios e muito quentes), proporcionam pouca redução de consumo em climas amenos. Nas cidades de Curitiba, Porto Alegre e São Paulo os vidros laminados de controle solar resultaram em desempenho ligeiramente melhor ou similar ao vidro duplo. Em climas quentes, como Recife, Salvador, Rio de Janeiro e Porto Alegre, vidros duplos promovem boa economia, alcançando, em Recife, maior redução do consumo, 121 MWh, em relação ao vidro laminado de controle solar para o modelo com WWR $60 \%$. Desta maneira, é necessário avaliar a relação custo $\mathrm{x}$ benefício da aplicação deste fechamento no Brasil. A economia obtida na conta de energia pode ser revertida para investimento na especificação de um vidro de melhor desempenho.

A aplicação de isolante térmico em viga de borda de fachadas revestidas por vidro apresentou redução considerável do consumo energético do edifício, principalmente naqueles localizados em cidades com temperaturas elevadas em grande parte do ano, onde o maior isolamento da envoltória reduz o ganho de calor, reduzindo a carga térmica interna.

Devido à importância das edificações no consumo de energia elétrica no Brasil, a presente pesquisa contribui para promover a redução do consumo energético de edifícios de escritórios condicionados artificialmente, por meio da geração de informações técnicas que auxiliam e dão suporte à tomada de decisões nas fases iniciais de projeto. Nesta pesquisa não foi considerada a integração da iluminação artificial com a natural, sendo esta uma limitação do trabalho.

\section{REFERÊNCIAS}

BESEN, P.; WESTPHAL, F. S. Uso de vidro duplo e vidro laminado no Brasil: avaliação do desempenho energético e conforto térmico por meio de simulação computacional. ENTAC.

Anais...Juiz de Fora, MG: 2012

BOUDEN, C. Influence of glass curtain walls on the building thermal energy consumption under Tunisian climatic conditions: The case of administrative buildings. Renewable Energy, v. 32, n. 1, p. 141-156, jan. 2007.

BURATTI, C. et al. Unsteady simulation of energy performance and thermal comfort in nonresidential buildings. Building and Environment, v. 59, p. 482-491, jan. 2012. 
CARVALHO, M. M. Q.; LA ROVERE, E. L.; GONÇALVES, A. C. M. Analysis of variables that influence electric energy consumption in commercial buildings in Brazil. Renewable and Sustainable Energy Reviews, v. 14, n. 9, p. 3199-3205, dez. 2010.

CAVALCANTE, R. DE C. D. Simulação energética para análise da arquitetura de edifícios de escritório além da comprovação de conformidade com códigos de desempenho. [s.l.] Universidade de São Paulo, 2010.

GRATIA, E.; DE HERDE, A. Greenhouse effect in double-skin facade. Energy and Buildings, v. 39, n. 2, p. 199-211, fev. 2007.

MOTTA, S. R. F. Análise da influência do vidro das janelas sobre o consumo energético das edificações. ENCAC. Anais...Ouro Preto, MG: ENCAC, 2007

NEVEEN, H. Double versus single skin facades in hot arid areas. Energy and Buildings, v. 40, n. 3, p. 240-248, jan. 2008.

NOH-PAT, F. et al. Thermal analysis for a double glazing unit with and without a solar control film ( $\mathrm{SnS}-\mathrm{CuxS})$ for using in hot climates. Energy and Buildings, v. 43, n. 2-3, p. 704-712, fev. 2011.

PALMER, C. M.; GENTRY, T. A Better Distinction for Standard Specifications of Low-E Coatings for Diverse Climate Conditions. PLEA. Anais...North Carolina at Charlotte USA: 2012

POIRAZIS, H.; BLOMSTERBERG, Å.; WALL, M. Energy simulations for glazed office buildings in Sweden. Energy and Buildings, v. 40, n. 7, p. 1161-1170, jan. 2008.

SANTANA, M. V.; GHISI, E. Influência de parâmetros construtivos relacionados ao envelope no consumo de energia em edifícios de escritório da cidade de Florianópolis. ENCAC.

Anais...Natal, RN: ENCAC, 2009

SHAMERI, M. A. et al. Perspectives of double skin façade systems in buildings and energy saving. Renewable and Sustainable Energy Reviews, v. 15, n. 3, p. 1468-1475, abr. 2011.

WESTPHAL, F. S. Análise de Incertezas e de Sensibilidade Aplicadas à Simulação de Desempenho Energético de Edificações Comerciais. [s.1.] Universidade Federal de Santa Catarina, 2007.

YAMAKAWA, M. A.; WESTPHAL, F. S. Influência do Percentual de Abertura nas Fachadas e do Fator Solardos Vidros na Etiquetagem do PROCEL / INMETRO: Método Prescritivo X Simulação. n. 1, p. 1-7, 2009.

YIN, R.; XU, P.; SHEN, P. Case study: Energy savings from solar window film in two commercial buildings in Shanghai. Energy and Buildings, v. 45, p. 132-140, fev. 2012. 